\title{
Serum hydroxybutyrate dehydrogenase (HBD) assays in the clinical laboratory
}

\author{
K. MONTAZEMI AND J. G. LINES \\ From the Biochemical Section, The John Bonnett Clinical Laboratories, Addenbrooke's Hospital, Cambridge
}

SYNOPSIS Measurement of serum hydroxybutyrate dehydrogenase (HBD) activity for suspected myocardial infarction will nowadays usually be carried out with a commercially available test kit. Four such kits have been compared and evaluated: British Drug Houses HBDH set, Boehringer Corporation LDH-1-Iso-enzyme ' $\alpha$-HBDH' kit, Calbiochem $\alpha-H B D H$ Statpack, and Eskalab $\alpha-\mathrm{HBDH}$ reagent tablets. Of the 100 sera examined, 60 were from patients believed to have suffered a recent myocardial infarction, and 40 samples were from patients aged between 45 and 65 years who had no known hepatic, renal, or cardiac pathology, these being used to determine the normal range for each kit. Under standardized conditions the activity found differed from kit to kit; the clinical value of the various assay systems in terms of their ability to discriminate between normal and pathological sera is assessed; and finally the cost and the convenience of use of each kit procedure are discussed. Theoretical and experimental evidence is provided in support of an assay temperature of $30^{\circ} \mathrm{C}$, and a plea is made for international agreement on enzyme assay conditions.

Since the demonstration in 1954 that the serum aspartate amino transferase (SGOT) activity rises following myocardial infarction (LaDue, Wróblewski, and Karmen, 1954), the biochemical diagnosis of acute myocardial damage by the measurement of serum enzyme activity has become an established practice. The transient nature of the SGOT rise after a myocardial infarct (Chinsky, Wolff, and Sherry, 1957; Dewar, Rowell, and Smith, 1958) led to investigations for other myocardial enzymes released into the systemic circulation as a result of the tissue damage. Although serum lactic dehydrogenase (LDH) activity was demonstrated to remain at above normal levels for longer than SGOT (Wróblewski and LaDue, 1955), its value was limited by its non-specific nature. The subsequent demonstration (Elliott and Wilkinson, 1961; Elliott, Jepson, and Wilkinson, 1962) that the LDH isoenzyme arising from heart muscle was more specific towards the substrate $\alpha$-ketobutyrate reduced this limitation, particularly so in their hands if the results were assessed in conjunction with the conventional LDH activity. The value of measuring the serum $\alpha$-hydroxybutyrate (HBD) activity, that is its reducing properties on the $\alpha$-ketobutyrate substrate in the diagnosis of myocardial infarction, was confirmed (Konttinen, 1961; Pagliaro and NotarReceived for publication 13 September 1971. bartolo, 1961) and has been favourably compared with that of measuring other serum enzymes (Elliott and Wilkinson, 1962; Pagliaro and Notarbartolo, 1962; Konttinen and Halonen, 1962; Rosalki, 1963; Preston, Batsakis, and Briere, 1964).

The measurement of the serum HBD activity may now be regarded as the most useful biochemical parameter for the diagnosis of a myocardial infarction which had occurred 36 or more hours previously (Stuart, Crawford, Forshall, and Owen, 1965). We recognize though that some laboratories which include serum LDH activity amongst their routine liver function tests may not consider it justified to make HBD assays available as well as LDH, but for all other laboratories the measurement of serum HBD activity should be part of the service offered. As an early result would normally be required and the number of requests for this service at any one time is unlikely to be large from the area served by any one laboratory, a convenient economical means of carrying out these small numbers of analyses is necessary. Subdividing bulk prepared reagents with deep frozen storage of the aliquots until required is one possibility. The availability recently of commercially prepared reagents in packs suitable for the analysis of one, five, 20 , or more sera at a time or within a defined short period, has provided a preferable alternative. The objects of the 
present work were to evaluate four such commercially available test packs and to determine the normal range for each kit in a similar population to that in which the assay would be called for in clinical practice. The four HBD assay packs were the British Drug Houses HBDH set, the Boehringer Corporation LDH-1-Isoenzyme ' $\alpha$-HBDH' kit, the Calbiochem $\alpha$-HBDH Statpack, and Eskalab $a-\mathrm{HBDH}$ reagent tablets.

To carry out an analysis it is only necessary to reconstitute the reagents with water, add the appropriate volume of serum, and monitor the NAD/NADH ${ }_{2}$ (nicotinamide adenine dinucleotide/ dihydrogen) interconversion under stable specified conditions. Amongst these conditions is temperature, and as might be expected at the present time when there is no international agreement on the performance of enzyme assays particularly in regard to temperature, the procedural details recommended by each manufacturer vary. The suggested temperatures range from 25 to $37^{\circ} \mathrm{C}$, but for a comparative study all assays should be carried out at a single temperature. The choice of $25^{\circ} \mathrm{C}$ would receive the support of the German enzymologists (International Union of Biochemistry, 1961) and others (Amador, Dorfman, and Wacker, 1963; Stambaugh and Post, 1966) and was strongly advocated by some participants in a recent British symposium, ${ }^{1}$ but in the same symposium equally strong theoretical arguments were put forward for standardization at $37^{\circ} \mathrm{C}$. The commercial availability of a reaction rate analyser whose technical features make the enzyme reaction most easily controlled at $35^{\circ} \mathrm{C}$ provided another possible temperature for the studies reported here. Standardization at $30^{\circ} \mathrm{C}$ appeared to us to be preferable, however, because this is the temperature recommended by the International Union of Biochemistry (1964) and has the support of the majority of members of the International Federation of Clinical Chemistry. Furthermore, use of this temperature eliminates the problems of early substrate exhaustion at higher temperatures and of measuring the extremely small optical density changes in sera with normal enzyme concentrations assayed at $25^{\circ} \mathrm{C}$ unless undesirably large quantities of serum are used. For the attainment and maintenance of this lower temperature, cooling as well as heating facilities are necessary in many laboratories. Nonetheless, some studies were made at $25^{\circ} \mathrm{C}$ to determine the effect on individual sera of changes in assay temperature.

\section{Subjects and Materials}

Serum samples for 100 patients have been assayed

' London, 25 February 1971 'Automation of U.V. Enzyme Assays'. Association of Clinical Biochemists, southern region Meeting. for HBD activity by each of the four test kits, in many instances in duplicate. Of these sera, 60 were sent to the laboratory for HBD assay because of suspected recent myocardial infarction or assessment of recovery after a confirmed infarct. The other 40 samples, which were used to determine the normal range for each kit, were from a control group of hospital inpatients, half of them male and half female, aged between 45 and 65 years, with no known hepatic, renal, or cardiac pathology. The majority of the female patients were awaiting gynaecological operations, the remainder, like the male patients, had been admitted to hospital for a variety of reasons, eg, subarachnoid haemorrhage, rheumatoid arthritis, and diabetes.

The presentation and cost of each of the four test packs is summarized in Table I. The composition of

\begin{tabular}{|c|c|c|c|c|c|}
\hline Kit & $\begin{array}{l}\text { Form of } \\
\text { Presen- } \\
\text { tation }\end{array}$ & $\begin{array}{l}\text { No. of } \\
\text { Tests per } \\
\text { Pack }\end{array}$ & $\begin{array}{l}\text { Minimum } \\
\text { Utilization } \\
\text { Rate }\end{array}$ & $\begin{array}{l}\text { Total } \\
\text { Price }\end{array}$ & $\begin{array}{l}\text { Cost } \\
\text { per Test } \\
(p)\end{array}$ \\
\hline BDH & Vials & 40 & $\begin{array}{l}20 \text { in } 5 \\
\text { days }\end{array}$ & $£ 2.10$ & 5.25 \\
\hline Boehringer & Vials & 60 & $\begin{array}{l}20 \text { in } 3 \\
\text { weeks }\end{array}$ & $£ 3.10$ & 5.16 \\
\hline $\begin{array}{l}\text { Calbio- } \\
\text { chem }\end{array}$ & Vials & 50 & 5 in 1 day & $£ 6.41$ & 12.82 \\
\hline Eskalab & $\begin{array}{l}\text { Simple } \\
\text { tablets }\end{array}$ & 20 & Singly & $£ 5.00$ & 25.00 \\
\hline
\end{tabular}

Table I Composition and cost of serum HBD kits

the assay solution as prepared from each kit is shown in Table II. The BDH (British Drug Houses) kit consists of two vials of lyophilized activating substrate and 10 vials of 'base substrate' or buffered $\mathrm{NADH}_{2}$; in this kit the buffer is $\mathrm{N}$-(2-acetamido)-2 amino ethane sulphonic acid (ACES) and sodium hydroxide with $0.9 \%$ albumin bovine fraction $\mathrm{V}$. One vial of substrate and as many of buffered $\mathrm{NADH}_{2}$ as required are reconstituted by the addition

\begin{tabular}{lllll}
\hline Kit & $\begin{array}{l}\text { Volume of } \\
\text { Buffered } \\
\text { Substrate } \\
(m l)\end{array}$ & $\begin{array}{l}\mathrm{NADH}_{2} \\
(\mu M)\end{array}$ & $\begin{array}{l}\text { a-Ketobutyrate } \\
(\mu M)\end{array}$ & $\begin{array}{l}\text { Buffer } \\
(\mu M)\end{array}$ \\
\hline BDH & 3.0 & 0.39 & 16 & $\begin{array}{l}\text { 1ACES/NaOH } \\
280\end{array}$ \\
Boehringer & 3.2 & 0.40 & 10 & $\begin{array}{l}\text { Phosphate } \\
150 \\
\text { Phosphate } \\
240 \\
\text { Calbiochem }\end{array}$ \\
Eskalab & 3.0 & 0.36 & 39 & $\begin{array}{l}\text { Phosphate } \\
200\end{array}$ \\
\hline
\end{tabular}

Table II Composition of the assay mixture for each serum $H B D$ activity determination

${ }^{1} \mathrm{~N}-(2$ - acetamido)-2 amino ethane sulphonic acid and sodium hydroxide with $0.9 \%$ bovine albumin. 
of a measured volume of water. In the Boehringer kit, the $\mathrm{NADH}_{2}$ and the buffer are in separate vials as well as the $\alpha$-ketobutyrate and require separate reconstitution and pipetting. Of the least stable reagent, $\mathrm{NADH}_{2}$, three bottles are provided in the Boehringer kit, each of which when reconstituted is stated to be stable for three weeks, and, as the amount of reagent is sufficient for 20 tests, the minimum utilization rate for this kit is 20 tests in three weeks (column 4, Table I). A similar calculation has been done for the other test kits; in each case it is assumed that one test requires about $3 \mathrm{ml}$ of reagent mixture.

For the Calbiochem Statpack procedure, a measured volume of water is added only to the $\mathrm{NADH}_{2}$ vial and after dissolution of the dried powder the complete contents of this vial are poured into a second vial containing the lyophilized $\alpha$-ketobutyrate. The volume of reagent is sufficient for five analyses, though recently a Fastpack kit has been made available with which the volume of reagent prepared is that for 50 analyses. In the present study, the Statpack has been used. As indicated in Table I, the Eskalab tablets are packed separately and are useable singly, though they are normally purchased in boxes of 20 tablets. Each tablet consists of measured amounts of $\mathrm{NADH}_{2} \alpha$-ketobutyrate and phosphate buffer, the approximate quantities in one tablet (there is stated to be some variation from batch to batch), that is in the assay solution for one test, are again shown in Table II.

\section{Method}

To ensure that first order kinetics held during the reaction and to maintain a constant temperature, a recording spectrophotometer (Unicam SP800) with a temperature controlled cuvette holder $(30 \pm$ $0.05^{\circ} \mathrm{C}$ ) was used. The volume of serum was standardized at $10 \mu \mathrm{l}$. Other than employing a recording specrophotometer instead of measuring the optical density at specific times and using a sample volume of $10 \mu \mathrm{l}$, the manufacturers' instructions were

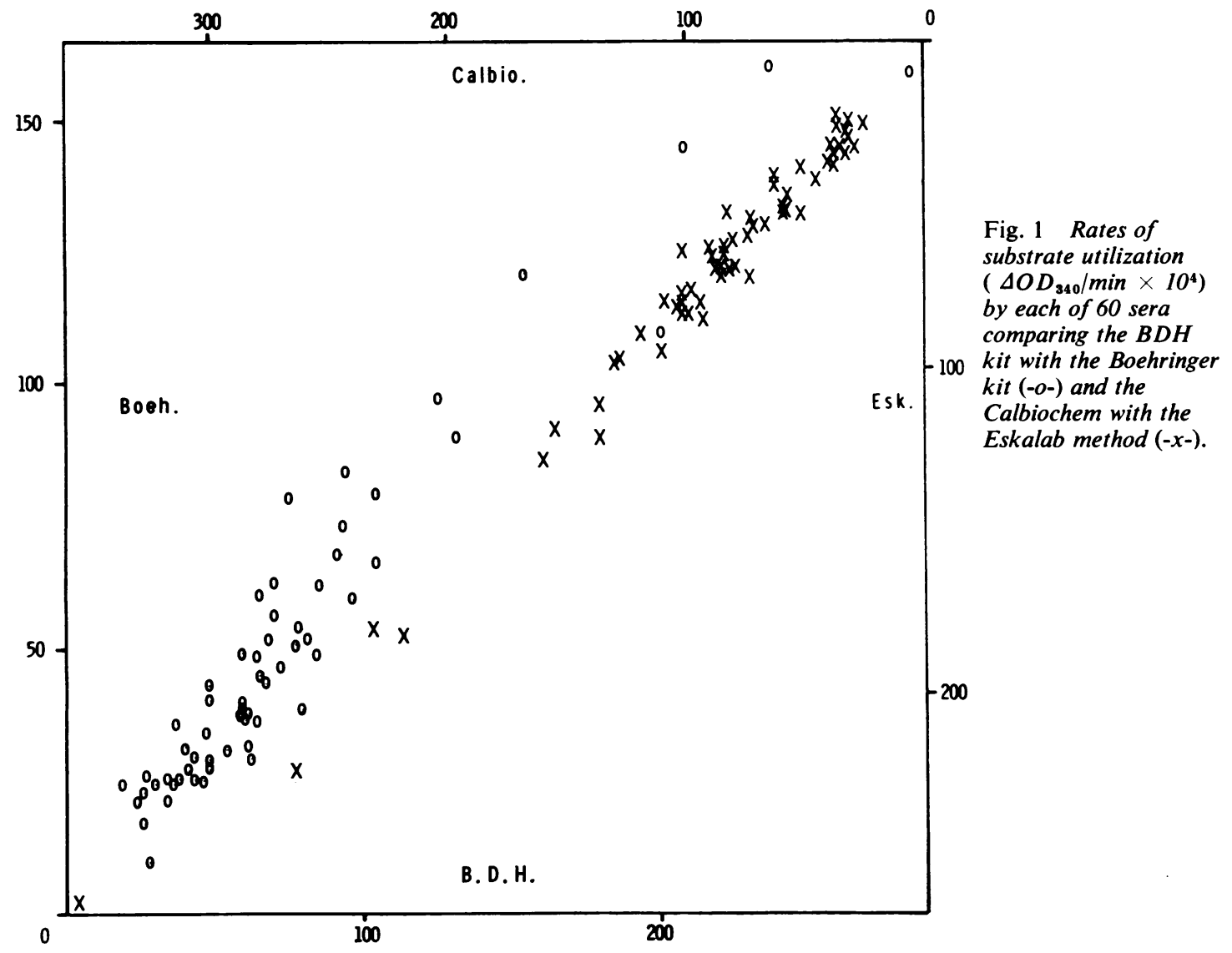


followed implicitly, particularly with regard to the preparation of reagents. The reconstituted BDH and Boehringer reagents were stored at $4^{\circ} \mathrm{C}$ between analyses, but at no time did the storage period exceed that recommended by the manufacturers. The Calbiochem and Eskalab reagents were used immediately after dissolution with water.

Before commencing an assay, all reagents were brought to $30^{\circ} \mathrm{C}$. Then, the measured volume of buffer, buffered coenzyme, or in the case of Calbiochem and Eskalab kits, the complete reaction mixture, was pipetted into a $10 \mathrm{~mm}$ light-path spectrophotometer cuvette, and after replacing the cuvette in its thermostated holder, a short time was allowed to elapse for complete re-equilibration. Serum $(10 \mu \mathrm{l})$ was then added to its cuvette from a 10 microlitre syringe and the optical density at 340 $\mathrm{nm}$ was recorded at one-minute intervals for about 30 minutes. For BDH and Boehringer assays the substrate $\alpha$-ketobutyrate, prewarmed to $30^{\circ} \mathrm{C}$, was added five minutes after the recording had begun.
For all assays the reaction was monitored for not less than 20 minutes, and the actual reaction rate was determined for a 10-minute period within this time, whilst the rate of change of optical density was linear.

The observed reaction rates $\left(\Delta O D_{340} / \mathrm{min}\right)$ were converted into conventional units of enzyme activity (International Units/litre, IU/1) by multiplying the observed rate for Boehringer kit assays by 51,610 and for the other three kits by 48,393 . These factors are derived from the extinction coefficient of $\mathrm{NADH}_{2}$, the volume of serum used and the total volume of the reacting mixture. The two values differ because the final assay volume using the Boehringer kit is $3.21 \mathrm{ml}$ compared with the 3.01 $\mathrm{ml}$ with the other test packs.

\section{Results}

The reaction rates, that is, the change in optical density at $340 \mathrm{~nm}$ per minute, found by each of the

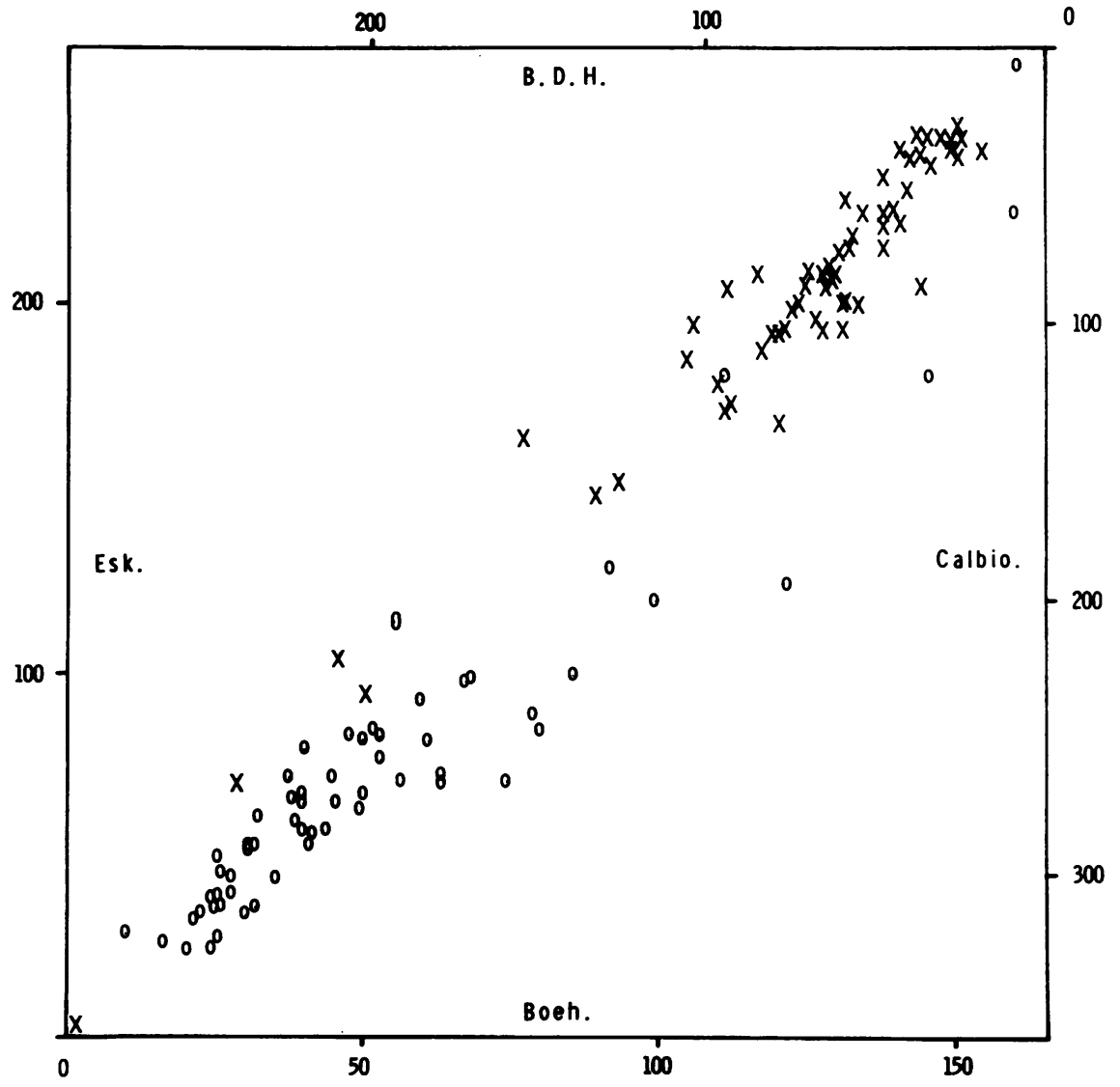

Fig. 2 As for Fig. 1 but comparing the $B D H$ and Calbiochem kits $(-x-)$ and the Boehringer with the Eskalab (-o-) kit. 
four test kits for the 60 sera from patients with known or suspected recent myocardial damage, are compared kit for kit in Figures 1 and 2. In the first figure the BDH results are compared with those found with the Boehringer kit and the Calbiochem test kit procedure results are compared with those found with the Eskalab tablets. In Fig. 2, the comparisons are of the Boehringer with Eskalab results and the $\mathrm{BDH}$ with Calbiochem. The $45^{\circ}$ trends in these scatter diagrams show that an approximate correlation exists between results over a wide range of activities. From the width of scatter, it appears that a closer correlation exists between the Calbiochem and Eskalab results than for example between the Boehringer and Eskalab results. These differences are quantitated in Table III in which the linear correlation ( $r$ ) between each pair of results for all possible paired comparisons is shown, together with similarly determined correlations for the $\mathbf{4 0}$ control samples. Eskalab and Calbiochem results correlate most closely, whilst the least correlation is found in the Boehringer and BDH results for the controls and between Boehringer and Calbiochem for the presumed cardiac or 'pathological' sera. Indeed, the relative activity obtained with the Boehringer kit was sometimes considerably different from those found with the other methods, as will be discussed later.

From the axes of Figs. 1 and 2 it is clear that differing degrees of activity are found with each of the kits; for example, the range of substrate utilization rates found with the Boehringer kit for the cardiac sera examined is about 10-160 units $\left(\Delta \mathrm{OD}_{340} / \mathrm{min}\right)$ whereas with the Calbiochem test pack it is about 20 to 340 units. The mean substrate utilization rates for each kit for both cardiac and control sera are shown in Table IV. For both types of sample, the activity with the Calbiochem test pack is about $80 \%$ greater than that achieved with the Boehringer kit for the same volume of serum. The serum HBD activities found with the BDH and Eskalab procedures are intermediate between those of the two other methods.

The results of analyses on the 40 control subjects are summarized in Table V, together with the normal values given by the manufacturer. Where the latter values were not stated for an assay temperature of $30^{\circ} \mathrm{C}$, those given were converted to their $30^{\circ} \mathrm{C}$ equivalents by use of the temperature coefficient recommended by the International Union of Biochemistry (1964), and two of the manufacturers. From Table V, it can be seen that in three cases the

\begin{tabular}{lllllll}
\hline Serum & Eska/Boeh & Eska/BDH & Eska/Calbio & Boeh/BDH & Boeh/Calbio & BDH/Calbio \\
\hline $\begin{array}{l}\text { Control } \\
(\mathrm{N}=40)\end{array}$ & 0.766 & 0.863 & 0.878 & 0.631 & 0.810 & 0.870 \\
$\begin{array}{l}\text { Cardiac } \\
(\mathrm{N}=60)\end{array}$ & 0.969 & 0.986 & 0.995 & 0.963 & 0.951 & 0.982 \\
\hline
\end{tabular}

Table III Coefficient of linear correlation between the reaction rates $\left(\triangle O D_{340} /\right.$ min) for each pair of methods for control sera and for cardiac sera

\begin{tabular}{lllll}
\hline Sera & Kit & & \\
\cline { 2 - 5 } & BDH & Boehringer & Calbiochem & Eskalab \\
\hline Control $(\mathrm{N}=40)$ & $0.0037 \pm 0.0009$ & $0.0025 \pm 0.0006$ & $0.0048 \pm 0.0010$ & $0.0041 \pm 0.0008$ \\
Cardiac $(\mathrm{N}=60)$ & $0.0075 \pm 0.0052$ & $0.0052 \pm 0.0033$ & $0.0090 \pm 0.0059$ & $0.0074 \pm 0.0047$ \\
\hline
\end{tabular}

Table IV Mean rates of substrate utilization $\left(\triangle O D_{340} / \mathrm{min}\right) \pm 1$ standard deviation found in control and cardiac samples of serum

\begin{tabular}{|c|c|c|c|c|}
\hline & \multicolumn{4}{|l|}{ Kit } \\
\hline & $B D H$ & Boehringer & Calbiochem & Eskalab \\
\hline Range (IU/I) & $87-290$ & $77-186$ & $145-334$ & $106-285$ \\
\hline $\begin{array}{l}\text { Mean (IU/I) } \\
\text { SD }\end{array}$ & $\begin{array}{l}177 \\
45\end{array}$ & $\begin{array}{l}131 \\
30\end{array}$ & $\begin{array}{l}231 \\
51\end{array}$ & $\begin{array}{l}200 \\
41\end{array}$ \\
\hline Mean \pm 2 SD & $87-267$ & $71-191$ & $129-333$ & $118-282$ \\
\hline $\begin{array}{l}\text { Stated normal range } \\
\text { (IU/1) }\end{array}$ & $79-170$ & Up to $190^{1}$ & $96-210$ & $104-220^{2}$ \\
\hline
\end{tabular}

Table V Serum HBD activity in control subjects (20 male and 20 female) between the ages of 45 and 65 years

${ }^{1}$ Stated normal ranges converted to $30^{\circ} \mathrm{C}$ from actual stated values at $25^{\circ} \mathrm{C}^{1}$ and $37^{\circ} \mathrm{C}^{2}$ by temperature correction factor of $6 \% /{ }^{\circ} \mathrm{C}($ International Union of Biochemistry, 1964) 
upper limit of normal stated by the manufacturer is considerably lower than 2 standard deviations above the experimentally determined mean, which as would be expected with our sample size $(N=40)$ is closely similar to the highest observed value. Blood was also examined from six other patients believed to have normal LDH status, but which on analysis gave abnormal HBD values with some kits, mainly Calbiochem and Eskalab; the results from these patients have been disregarded, but these observations emphasize that different kits can create differing interpretations of patient status.

Finally, the reproducibility of results attainable with different batches of each kit was determined and compared with the within-batch analytical precision. For kit reproducibility assessment, four batches of each kit were used to analyse one normal serum and one cardiac serum with an HBD activity $50 \%$ greater than the upper limit of normal. The analyses were performed in duplicate. The coefficient of variation for each group of eight analyses is shown in Table VI. We are aware that these values are

\begin{tabular}{lllll}
\hline Serum & \multicolumn{1}{l}{ Kit } & & & \\
\cline { 2 - 5 } & BDH & Boehringer & Calbiochem & Eskalab \\
\hline Control & $19 \cdot 6^{1}$ & $17 \cdot 1$ & $1 \cdot 3$ & $5 \cdot 6$ \\
Cardiac & $17 \cdot 3$ & $9 \cdot 8$ & $2 \cdot 4$ & $3 \cdot 8$ \\
\hline
\end{tabular}

Table VI Analytical coefficients of variation between four batches of each kit ${ }^{1}$

'The high coefficients of variation obtained with this kit can be accounted for by one batch producing activities which were on average $45 \%$ greater than those of the other three tested.

slightly misleading in that a more desirable experiment would have been a single analysis on each of eight kits, but we calculate that this would have affected the coefficients of variation by at the most $5.6 \%$ (Eskalab) and by a much lesser amount in all other cases. The within-batch analytical precision was determined by performing duplicate analyses on 12 samples of serum whose HBD activity evenly covered the normal and pathological ranges. Subdividing these twelve sera into the six with normal activity and six of higher activity, the coefficients of varia-

\begin{tabular}{|c|c|c|c|c|}
\hline \multirow[t]{2}{*}{ Serum } & \multicolumn{4}{|l|}{ Kit } \\
\hline & $B D H$ & Boehringer & Calbiochem & Eskalab \\
\hline $\begin{array}{l}\text { Normal } \\
\text { activity }\end{array}$ & $5 \cdot 3$ & $6 \cdot 0$ & $2 \cdot 4$ & $1 \cdot 6$ \\
\hline High activity & $2 \cdot 1$ & 1.9 & $2 \cdot 0$ & $1 \cdot 1$ \\
\hline All 12 & $2 \cdot 8$ & $2 \cdot 7$ & $2 \cdot 2$ & $1 \cdot 3$ \\
\hline
\end{tabular}

Table VII Within-batch coefficients of variation calculated from duplicate analyses on six or 12 sera tion are shown in Table VII, the standard deviation for each six pairs of results being calculated from the formula $\mathrm{SD}=\sqrt{\frac{\overline{\mathrm{d}^{2}}}{\mathrm{~N}-1}}$, together with the overall coefficients of variation.

\section{Discussion}

The meaningful measurement of HBD activity in whole serum for the diagnosis or monitoring of a $\vec{O}$ recent myocardial infarction is made difficult $\vec{\overrightarrow{ }}$ because the substrate $\alpha$-ketobutyrate is reduced, $\omega$ though at differing rates, by the isoenzymes of lactate dehydrogenase present in the serum (Rosalki and Wilkinson, 1960). Furthermore, the contribu- or tion of each isoenzyme to the observed activity will $\stackrel{N}{\sim}$ vary with different substrate and coenzyme con- $\vec{A}$ centrations and also with the temperature at which 0

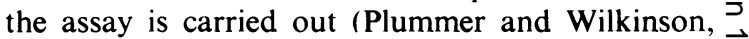
1963; Smith, 1971). It is not surprising, therefore, Tा that when sera were assayed for HBD activity by $\mathbb{D}$ four commercially available systems whose compositions varied, the rates of substrate utilization differed. However, the principal requirement of the $\vec{\bullet}$ clinical laboratory upon a serum HBD assay systeg $N$ is that it should differentiate sera of patients who hed suffered recent myocardial damage from those wh have not, and it is this criterion which must assessed in the first place.

For reasons given earlier, an assay temperature of $30^{\circ} \mathrm{C}$ was considered preferable. At this temperature, the results of Table IV suggest that the Boehringer $\overrightarrow{\bar{O}}$ assay system is better able to differentiate normal sera 3 and sera from patients with myocardial damage than are the systems provided by other manufacturers, because the mean 'pathological' value exceeds the $\overline{\widehat{O}}$. mean control value by the greatest proportion:$(+108 \%)$. The BDH system is only slightly less 3 . discriminatory $(-102 \%)$, but Calbiochem and Eskalab assays give markedly lower proportional changes $(+89 \%$ and $+80 \%$ respectively). In a separate preliminary experiment on effects of temperature in which a small number of normal and $\frac{7}{3}$ slightly abnormal sera had been compared, a similar conclusion had been reached for assays at $\mathcal{N}$ $30^{\circ} \mathrm{C}$, but on lowering the assay temperature to $25^{\circ} \mathrm{C} \mathrm{N}$ the difference between the activities of these two N groups of sera had decreased by an average of $37 \% \mathrm{\omega}$ (range $33-40 \%$ ), suggesting that at $25^{\circ} \mathrm{C}$ the discrimination between normal and cardiac sera was less than at the higher temperature. Our choice of $\stackrel{\Phi}{\oplus}$ $30^{\circ} \mathrm{C}$, therefore, received some experimental support, $\stackrel{+}{\square}$ though this must be regarded as tentative until a much larger series of comparisons with concomitant $\vec{\Phi}$ knowledge of the isoenzyme configuration is $\frac{?}{\mathbb{Q}}$ 
undertaken. Should temperatures of 35 or $37^{\circ} \mathrm{C}$ be used for the assay, it is likely that substrate concentrations higher than are present in either the BDH or Boehringer systems would be desirable. International agreement on the recommended assay temperature is highly desirable.

Although it would appear that for analyses at $30^{\circ} \mathrm{C}$, the Boehringer kit is preferable, the differences were not statistically significant. Secondary considerations for the selection of a commercial test pack thus became important. Foremost of these must come the reproducibility of the kit in manufacture followed by its cost and convenience of use. Considering the latter criteria first, whilst Eskalab tablets can be used singly and are extremely convenient, their unit test price is almost five times as much as either the BDH or Boehringer assays. Determinations carried out with the Calbiochem kit have a unit cost approximately half that of the Eskalab procedure. In the average sized hospital laboratory wastage of reagents would probably be least with the Boehringer kit with which 20 assays can be carried out in up to three weeks. Laboratories with a larger call for serum HBD assays might prefer the similarly priced but less stable BDH presentation as only two pipettings are required other than the addition of serum compared with three pipettings using the Boehringer assay.

As for kit reproducibility, the results of Table VI suggest that manufacturing techniques require careful attention, presumably in the dispensing of the individual reagents. The magnitude of the desirable improvement is indicated by the differences in analytical precision between and within batches (Tables VI and VII). In the meanwhile, laboratories should be fully aware of these potential discrepancies and institute the appropriate quality control procedures. At the same time it is of value to emphasize that the validity of results also depends upon care in the reconstitution of reagents, accurate dispensing of both reagents and serum, and elimination of organic solvents from the reaction cuvettes. The $10 \mu \mathrm{l}$ volume of serum sample may be recommended for general use because substrate exhaustion is unlikely to occur at any level of enzyme activity, thereby eliminating the need for repeat analyses; the reaction rates even with normal sera can be precisely measured, certainly over a 10 -minute period. The use of temperatures other than that normally employed must be deprecated because of the wide range of temperature correction factors found experimentally (see below) and the alterations in optimum reagent concentrations and individual isoenzyme activity with temperature (Smith, 1971).

It was disturbing to note the discrepancies between the normal ranges stated by the manufacturers and those found in this study. In only one case (Boeh- ringer Corporation) was there agreement, though subsequently a second manufacturer (British Drug Houses) has agreed with our findings and is taking appropriate action. Many different normal ranges have been reported in the literature (Wilkinson, 1965), perhaps in part because of the choice of normal subjects and in some cases because of the low numbers studied. We believe the selection of our own control subjects as the major 'at risk' age group, to be important. In attempting to translate these results to temperatures other than $30^{\circ} \mathrm{C}$, the limitations should be appreciated-for 12 sera with activities in or near the normal range, which were analysed at 25 and $30^{\circ} \mathrm{C}$ by the $\mathrm{BDH}$, Boehringer and Eskalab procedures, although the mean temperature coefficient was $6 \cdot 1 \% /{ }^{\circ} \mathrm{C}$, the range found was $0 \cdot 6-14 \cdot 5 \% /{ }^{\circ} \mathrm{C}$ with highest values for the Eskalab procedure (Montazemi, unpublished).

\section{Conclusions}

This work has demonstrated that provided care is taken in the analytical technique, meaningful serum HBD activity measurements can be carried out with any one of the four test packs examined, though batch variability in the kits may contribute significantly towards errors. Better discrimination between normal sera and sera from patients with myocardial damage can be obtained at lower rather than higher substrate and coenzyme concentrations despite the fact that at low concentrations activity is submaximal, and that this discrimination appears to be enhanced at $30^{\circ} \mathrm{C}$ compared to $25^{\circ} \mathrm{C}$. Of the four kits tested, those produced by British Drug Houses Ltd and the Boehringer Corporation would be preferable both on account of their composition and cost. The selection of one or other of these would probably depend on the number of HBD assays performed. From our data we can find no reason to criticize BDH for their replacement of phosphate as the buffer with the ACES/ $\mathrm{NaOH}$ system, other than perhaps that the normal range found with this kit is wider than that for the other systems; indeed one might speculate that it is the presence of this buffer which creates high activity in the presence of low substrate concentrations.

We greatly appreciate the interest of Professor $\mathrm{H}$. Lehmann who also provided the facilities for this work to be undertaken, and Dr N. E. M. Harker who supplied all the blood samples and clinical liaison. Each of the manufacturers generously supplied kits and their helpful interest in this study is gratefully acknowledged. K.M. was in receipt of a British Council scholarship. 


\section{References}

Amador, E., Dorfman, L. E., and Wacker, W. E. C. (1963). Serum lactic dehydrogenase activity: an analytical assessment of current assays. Clin. Chem., 9, 391-399.

Chinsky, M., Wolff, R. J., and Sherry, S. (1957). Serum transaminase activity: a comparison of the pyruvic and oxalacetic transaminases. Amer. J. med. Sci., 233, 400-408.

Dewar, H. A., Rowell, N. R., and Smith, A. J. (1958). Serum glutamic oxalacetic transaminase in acute myocardial infarction. Brit. med. J., 2, 1121-1125.

Elliott, B. A., and Wilkinson, J. H. (1961). Serum alpha-hydroxybutyric dehydrogenase in myocardial infarction and in liver disease. Lancet, 1, 698-699.

Elliott, B. A., and Wilkinson, J. H. (1962). The relative efficiencies of some serum enzyme tests in the diagnosis of myocardial infarction. Lancet, 2, 71-72.

Elliott, B. A., Jepson, E. M., and Wilkinson J. H. (1962). Serum alphahydroxybutyrate dehydrogenase: a new test with improved specificity for myocardial lesions. Clin. Sci., 23, 305-316.

International Union of Biochemistry (1961). Report of the Commission on Enzymes, pp. 8, 10, and 45.

International Union of Biochemistry (1964). Recommendations on nomenclature and classification of enzymes. In Comprehensive Biochemistry, edited by M. Florkin and E. H. Stotz, ch. 13, p. 7. Elsevier, Amsterdam.

Konttinen, A. (1961). Alpha-hydroxybutyric dehydrogenase in the detection of myocardial infarction. Lancet, 2, 556.

Konttinen, A., and Halonen, P. I. (1962). Serum alpha-hydroxybutyric dehydrogenase (HBD) in myocardial infarction: comparison with glutamic oxalacetic transaminase (GOT) and lactic dehydrogenase (LDH). Amer. J. Cardiol., 10, 525-531.
LaDue, J. S., Wróblewski, F., and Karmen, A. (1954). Serum glutamic oxaloacetic transaminase activity in human acute transmural myocardial infarction. Science, 120, 497-499.

Pagliaro, L., and Notarbartolo, A. (1961). Alpha-hydroxybutyric dehydrogenase in the detection of myocardial infarction. Lancet, 2, 1261.

Pagliaro, L., and Notarbartolo, A. (1962). Alpha-hydroxybutyric dehydrogenase in diagnosis of myocardial infarction. Lancet, 1 , 1043-1045.

Preston, J. A., Batsakis, J. G., and Briere, R. O. (1964). Serum alpha-hydroxybutyrate dehydrogenase: a clinical and laboratory evaluation in pa.ients with myocardial infarction. Amer.J. clin. Path., 41, 237-243.

Plummer, D. T., and Wilkinson, J. H. (1963). Organ specificity and lactate-dehydrogenase activity. 2 . Some propertles of human heart and liver preparations. Biochem. J., 87, 423-429.

Rosalki, S. B., and Wilkinson, J. H. (1960). Reduction of alphaketobutyrate by human serum. Nature (Lond), 188, 1110-1111.

Rosalki, S. B. (1963). Serum alpha-hydroxybutyrate dehydrogenase: A new test for myocardial infarction. Brit. Heart J., 25, 795-802.

Stambaugh, R., and Post, D. (1966). Effects of tissue extracts and temperature on lactate dehydrogenase isoenzymes. Biochim. biophys. Acta (Amst.), 122, 541-543.

Smith, A. F. (1971). The effect of temperature on LDH and alphaHBDH assay. Unpublished observations.

Stuart, J., Crawford, I. C., Forshall, J., and Owen J. A. (1965). Serum alpha-hydroxybutyrate dehydrogenase in myocardial infarction. Brit. med. J., 1, 423-425.

Wilkinson J. H. (1965). In Isoenzymes (Biochemical Monographs, edited by C. Long), pp. 75. Spon, London.

Wróblewski, F., and LaDue, J. S. (1955). Lactic dehydrogenase activity in blood. Proc. Soc. exp. Biol. (N.Y.), 90, 210-213. 